\title{
A COGNITIVE-RELAXATION-VISUALISATION INTERVENTION FOR ANXIETY IN WOMEN WITH BREAST CANCER
}

\section{Colinda D Linde}

Rand Afrikaans University

\author{
Anita D Stuart \\ Professor, Department of Psychology, Rand Afrikaans University \\ Corresponding author: adst@lw.rau.ac.za
}

Keywords: Breast cancer; Cognitive-relaxation-visualisation; anxiety; diagnosis; female health

\begin{abstract}
The aim of this study was twofold. Firstly, to design a cognitive-relaxation-visualisation intervention with the aim of reducing both overt and covert anxiety associated with the diagnosis and treatment of breast cancer. In addition to the creation of a suitable intervention, the aim of the present study was to ascertain the efficacy of the intervention in two groups of randomly selected female subjects, the one group ( $N=72)$ being pre-diagnosis (awaiting mammogram results) and the other group $(N=16)$ being post-diagnosis (beginning radiation therapy). A Solomon four group design was used for the pre-diagnosis group and a pre-test - post-test control group design was utilised for the post-diagnosis group. The IPAT Anxiety Scale was used to measure the variables of overt and covert anxiety. Qualitative information regarding the intervention was obtained by means of a delayed interview. The results indicated that while the intervention had the effect of reducing anxiety for both groups, a pre-test sensitisation effect was also observed in the pre-diagnosis group. It emerged that patients had perceived the presence of an empathic individual at the time of diagnosis and early in treatment as being of greatest value in reducing anxiety.
\end{abstract}

\section{OPSOMMING}

Die doel van hierdie studie was tweeledig. Eerstens is daar gepoog om 'n kognitiewe ontspanningsvisualiseringsintervensie te ontwerp wat die vermindering van overte en koverte angs geassosieer met die diagnose en behandeling van borskanker ten doel het. Tesame met die ontwerp van 'n geskikte intervensie was die tweede doel om die doelmatigheid van die intervensie te toets in twee groepe bestaande uit toevallig geselekteerde vrouens. Die een groep ( $N=72$ ) kan beskryf word as pre-diagnose (afwagtend van mammogramresultate) en die tweede groep $(N=16)$ as post-diagnose (aanvang van bestralingsterapie). ' $n$ Solomon viergroep ontwerp was gebruik ten opsigte van die pre-diagnose groep en 'n pretoets-posttoets kontrolegroep ontwerp was gebruik vir die postdiagnose groep. Die IPAT Angsskaal was gebruik om overte en koverte angs te meet. Kwalitatiewe inligting aangaande die intervensie was verkry deur middel van 'n vertraagde onderhoud. Die resultate toon dat, alhoewel die intervensie wel verminderde angs tot gevolg gehad het vir beide groepe was ' $n$ pretoets sensitiseringseffek waargeneem in die prediagnose groep. Dit blyk dat die teenwoordigheid van 'n empatiese individu ten tye van diagnose asook vroeg in die behandelingsfase deur pasiënte as die waardevolste faktor beskou is ten einde angs te verminder. 


\section{INTRODUCTION}

Being faced with the idea of breast cancer is a stressful event for anyone, whether awaiting the diagnosis, anticipating or actually undergoing treatment for the cancer. Recently, there has been growing interest in the literature regarding these issues, especially the psychological reactions to diagnosis, radiation treatment (Farragher, 1998:166; Greer, 1999:237), the manner in which a patient is informed of a diagnosis, as well as their adjustment to treatment (Ambler, Rumsey, Harcourt, Khan, Cawthorn \& Barker, 1999:445; Bryant, Sackville, Dang, Moulds \& Guthrie, 1999:1781; Edelman, Lemon, Bell \& Kidman, 1999:474; Rusten, Wiklund, Hanestad \& Moum, 1998:236). Breast cancer is regarded as the most common cancer in women and statistics show that one in every 36 women will be diagnosed with breast cancer during her lifetime (Cansa, 2002). The incidence of breast cancer however differs significantly between races ranging from one in every 81 black women to one in every 13 white women in South Africa (Cansa, 2002).

It is known that a diagnosis as well as experience of cancer is distressing, with common psychological reactions at diagnosis including anxiety, anger, depression or denial (Constantini, Musso, Viterbori, Bonci, Del Mastro, Garrone, Venturini \& Morasso, 1999:121; Oktay, 1998:149). This is not a new discovery. However, what is more recent is the focus on what can be done to modify these reactions, rather than just observe them. There appears to be a trend emerging where the aim of later studies is to identify possible psychological interventions that could reduce distress and anxiety at diagnosis or treatment of cancer, thereby facilitating coping and adjustment. However, most of these authors have indicated that their findings are exploratory and that much replication and further study is required (Cimprich, 1999:185; Mose, Rahn, Budischewski, Zander-Heinz, Adamietz, Bormeth, Thilmann \& Bottcher, 1999:112).

It is therefore clear that a need exists for the study of psychological intervention in cancer patients. However, Spiegel, Morrow, Classen, Raubertas, Stott, Mudalier, Pierce, Flynn, Heard and Riggs (1999:484) have reviewed recent studies and conclude that although as many as $80 \%$ of breast cancer patients report signifi- cant distress during initial treatment, there is little as yet in the way of systematic psychological intervention for women coping with these stressors. They argue that this area of study is a vital one and that where there have been exploratory interventions, these have been associated with improved mood, coping and adjustment.

Anxiety is likely to impair one's level of functioning such as concentration levels at a time when an individual must make important health decisions. It is also known that prolonged anxiety has immunosuppressive effects (Singh, 1999:34) that may impact negatively on the course of the illness. In the case of breast cancer, there is speculation as to the role of anxiety at the time of diagnosis and during the course of treatment (Oktay, 1998:149; Singh, 1999:67). As anxiety is a stressor which may thus have immunosuppressive effects (Schlebusch \& Van Oers, 1999:30) it would appear relevant to explore the modification of anxiety at preand post- diagnosis of breast cancer.

In the light of abovementioned, there is therefore a strong motivation for this study, which will investigate whether an original intervention designed to reduce anxiety at a pre- as well as post- diagnosis stage of breast cancer, is effective. This study will attempt to fill a gap indicated in the literature, incorporate elements from interventions with proven efficacy in anxiety reduction into an original intervention, and will also be the first of its kind in South Africa. It is envisaged that should this intervention prove successful it can be taught to a variety of health care professionals who come into contact with the cancer patient and who the literature have indicated as relevant in this context. Such professionals would include nurses (Cimprich, 1999:187), psychotherapists and cancer counsellors (Hellbom, Brandberg, Glimelius \& Sjoden, 1998:247; McQuellan, Wells, Hoffman, Craven, Russell, Cruz, Hurt, DeChatelet, Andrykowski \& Savage, 1998:208) and physicians (Hyodo, Eguchi, Takigawa, Segawa, Hosokawa, Kamejima \& Inoue, 1999:397).

\section{AIMS AND OBJECTIVES}

After a review of the cancer literature it was decided that an original cognitive- relaxation-visualisation intervention would be designed and utilised with a group of pre- diagnosis patients who were waiting for mammo 
gram results as well as group of post-diagnosis patients receiving radiation therapy for breast cancer. The intervention would aim to reduce anxiety, which would be measured by the IPAT Anxiety Questionnaire, and anxiety would be separated into covert, unconscious versus overt, conscious anxiety. Qualitative information would also be obtained via a delayed interview approximately one year after the intervention, to shed light on the way in which the intervention had influenced anxiety at the time of diagnosis or treatment. The aim of such retrospective information would be to identify elements of the intervention that had remained in memory after a year and which would therefore have been the most meaningful components of the intervention, for that patient. There is as much a need to investigate anxiety, as there is to explore psychological intervention in illness research, therefore quantitative and qualitative information for both of these areas would be obtained and integrated.

In order to operationalise the goals and motivations for this study, the research question was set out as follows: does an original cognitive-relaxation-visualisation intervention bring about statistically significant changes in the variables of covert and overt anxiety in (a) a sample of women awaiting mammogram results (pre- diagnosis) and (b) a sample of women undergoing radiation therapy (post- diagnosis)? Further, on delayed interview, is the cognitive-relaxation-visualisation intervention recalled as having brought about a reduction in covert and overt anxiety variables?

\section{METHODOLOGY}

\section{Subjects and selection procedure}

The sample for the pre-diagnosis group $(\mathrm{N}=72)$ consisted of women with breast lumps, undergoing mammograms to screen for breast cancer. Ages ranged between 29 and 60 years with an average of 42 years. The subjects in the post-diagnosis group ( $N$ $=16$ ) were women who had been diagnosed with breast cancer, had had surgery and were now about to undergo radiation therapy. Ages ranged between 32 and 51 years, with an average age of 44 years. For both groups, there were a variety of religious orientations, educational levels varied from Matric to three years of tertiary education, and all were of middle class socio- economic status. Most of the participants were married or in stable relationships. Various exclusion criteria were assessed for in a biographic interview, with concurrent medical or psychological illness being the main exclusions criteria. Finally, participants were drawn from radiation and oncology centres in the same geographic area.

\section{Instruments}

A combined biographic and clinical interview was done at the beginning of each interaction with a subject. Biographic details such as age, cancer history and educational level were obtained. The clinical interview assessed for the presence of serious medical illness such as diabetes, as well as psychological disorders such as depression or panic. These factors were all grounds for exclusion.

The IPAT Anxiety Scale (Cattell, 1963:4) was compiled to provide a rapid evaluation of manifest (free-floating) anxiety, regardless of current conditions or immediate situation. It was developed from research with the 16 Personality Factor test. Its five components represent the most important components of the second-order anxiety factor of the 16PF, namely, Factors C-(egoweakness), L+(suspiciousness), O-(guilt proneness), Q3-(lack of self-sentiment) and Q4+(frustration/tension).

Each component comprises an equal number of items measuring (a) overt or symptomatic anxiety and (b) covert or unconscious anxiety. Total scores can be calculated for each of these components, as well as a total anxiety score. While scores can also be obtained for each component's second- order factors as detailed above, it is not common practice to do so for research purposes. Rather, the author (Cattell, 1963:15) advises that scores for overt anxiety, covert anxiety and total anxiety are best used in order to estimate an individual's conscious, unconscious and general anxiety levels respectively. The symptomatic (overt) versus covert scores can determine the extent to which an individual is aware of his/her own anxiety, and perhaps the degree to which $\mathrm{s} / \mathrm{he}$ consciously wishes to express it. The total score is a global estimate of the individual's general degree of anxiety, though it is merely an average of the overt and covert scores and would not have added value to the present study. Therefore, for this 
study, covert and overt anxiety scores were assessed, but the total anxiety was not calculated. There are thus several scores obtainable on this measure, though they translate into two variables, namely covert and overt anxiety.

On the questionnaire, the twenty cryptic items that provide the covert anxiety score are formulated relatively indirectly, so that a testee cannot readily guess their aim. The twenty more direct, symptomatic items serve as a report of actual symptoms, awareness of one's problems and possibly indicate when attempted distortion or overemphasis of symptoms occurs. These items provide a score to indicate overt anxiety. It has been found that those giving the least verbal indications of hostility display the most unconscious anxiety, while those tending to express hostility physically have more conscious anxiety (Cattell, 1963:14; Owen \& Taljaard, 1989:67).

Information on the construct validity of the Scale is provided in the manual (Cattell, 1963:13). The authors are of the view that one way in which construct validity of the Scale can be estimated, is by correlating it with another instrument that measures the same anxiety factor. As no such instrument was available to them, they hypothesised that maladjustment as measured by the National Bureau (NB) Adjustment Questionnaire of the then National Bureau of Educational and Social Research, would exhibit a relationship with anxiety. The various fields of the NB Adjustment Questionnaire were then correlated with the A score (covert anxiety), the $B$ score (overt anxiety) and the total score (average of $A$ and B scores) of the IPAT Anxiety Questionnaire, and results point to the construct validity of the questionnaire (Cattell, 1963:13).

Norms are available for white South Africans, male and female, aged 15 and upward. The reliability of the IPAT Scale was calculated with the test-retest and split-half methods, as well as with the Kuder-Richardson Formula 20. The reliability co-efficients for the scale as a whole vary between 0.76 and 0.84 , and can be regarded as satisfactory. The author of the IPAT (Cattell, 1963:14) regards the test-retest coefficients as the best means of assessing reliability of the measure. Cattell re-tested after approximately two weeks, as data for the calculation of stability coefficients (test-retest after a long interval) are not yet available, and found satis- factory reliability for the scale.

In the present study, the IPAT Scale was used to assess covert and overt anxiety with an interval of approximately 90 minutes before retesting. There is no data available on test-retest reliability. In the light of this information, it was decided not to wait for the twoweek interval before retest, as reported in the IPAT Anxiety Scale manual. Therefore, in the present study anxiety levels would be re-tested after a 90 minute interval in the experimental groups, with the pre-test being conducted first, then an intervention of approximately 35 minutes, and finally a post-test administration of the IPAT 60 minutes after the intervention. It was proposed that the measure would be measuring the same type of anxiety at this interval, which is the crux of testretest reliability.

\section{Procedure}

After the pre-test assessments the intervention was introduced to the experimental groups to which subjects had been randomly allocated. The intervention was explained to each participant as 'a way to help them cope better' with (a) waiting for mammogram results (pre-diagnosis group) and (b) undergoing radiation therapy (post-diagnosis group). The exact way in which the intervention would improve coping was not elaborated on as yet. The intervention was then conducted directly after explanation, and took approximately 35 minutes to explain, demonstrate and practise. For the pre-diagnosis group the mammogram had been done at this stage and the participants were waiting for results. There was still a delay of up to an hour after the intervention before subjects were notified of mammogram results, and during this time they were alone or with strangers. Directly after teaching the intervention and allowing the patient to practise, the researcher excused herself citing reasons such as needing to check in with another subject, before returning to perform the post-test approximately 60 minutes later. Many patients reported using the intervention or sections thereof to calm themselves during this period.

For the post-diagnosis group (radiation) the pre-test questionnaires were done first followed by the intervention. Questionnaires and intervention were done when anxiety was highest, shortly before simulation or 
radiation therapy commenced. The actual radiation procedure is of short duration, with approximately five minutes of actual radiation occurring. However, the preparation for the procedure as well as interruption of the procedure every few minutes to adjust the patient's position, results in a longer exposure of the patient to the radiation therapy context. There were approximately 60 to 90 minutes between the pre-test and intervention, and the post-test questionnaires that were done shortly after the simulation. Patients reported using the intervention to allay distress at being isolated in a room for the treatment as well as to cope with the side effects of treatment.

At the end of both studies those subjects who had requested feedback about their performance on the IPAT Anxiety Scale, or who wanted to know the results of the study, were provided with such.

The intervention designed for this study combined relaxation, visualisation and a cognitive component. The relaxation component was that of deep-diaphragmatic breathing as researched by Fried (1993:2) and this component aimed to reduce anxiety via activating the parasympathetic nervous system that induces a state of calm. The visualisation component was adapted from the visualisation elements proposed by Simonton (Kidman, 1983:5) and took the form of visualising a peaceful image using all the senses to maintain this image. After review of the literature it could be concluded that a sense of personal control during adversity, results in a sense of mastery and lowered levels of anxiety (Suls, David \& Harvey, 1996:716; Zuckerman, Knee, Kieffer, Rawsthorne \& Bruce, 1996:440). Therefore an original cognitive component was designed, whereby the subject was informed of the relationship between anxiety and control, followed by an explanation of how one might achieve a realistic sense of control during adverse circumstances such as pre- diagnosis and at the onset of radiation treatment.

The intervention was performed by the same researcher for both the pre- and post-diagnosis groups, and was the same for all participants. The intervention began with a cognitive explanation of effective coping, and an explanation of the way in which anxiety is interrelated with perceived control. This part of the intervention indicated that there is an alternate way of viewing the situation than being anxious about an uncontrollable factor, such as notification of diagnosis or onset of an unfamiliar treatment such as radiation therapy. The relaxation and visualisation components followed the cognitive one, in order to provide tangible alternatives to anxiety, in that these techniques could potentially be applied immediately as means of relaxation and regaining of control. The techniques could even function as a means of distraction while waiting for the diagnosis or during the first simulation (radiotherapy) session. The relaxation intervention was taught by showing patients deep diaphragmatic breathing which is known to activate the parasympathetic nervous system and therefore reduce autonomic arousal (Everly \& Rosenfeld, 1981:50). This type of breathing encourages breathing deeply and more fully, which increases the tidal volume of oxygen and therefore decreases breathing rate, which in turn reduces anxiety (Fried, 1993:21). Patients all practised the breathing for several minutes, with the researcher as coach. The patients were then instructed in the visualisation component, which entailed imagining a pleasant place using all their senses to create a detailed impression. This is similar to the visualisation technique used by Simonton (Fried, 1993:21) but without a visualisation of cancer cells being destroyed. This part was excluded as the present study focused on mediating anxiety rather than as a treatment aid.

The wording remained consistent across all subjects. The only variation occurred in whether they had preand/ or post-tests, as well as the intervention.

\section{Statistical analysis}

The parametric statistical analyses used for the prediagnosis groups were:

1. The Paired Samples t-test for ascertaining within-group differences, and

2. The Independent Samples t-test for ascertaining between-group differences.

The non-parametric statistical procedures used for the post-diagnosis groups were:

1. The Wilcoxon Signed Ranks test for ascertaining within-group differences, and

2. The Mann-Whitney Test for ascertaining between-group differences. 
The Kolmogorov-Smirnov test was used to assess normality of distribution of the population for the independent samples (SPSS, 1999).

\section{RESULTS}

Cattell (1963:3) described covert anxiety as occurring at an unconscious, physiological, autonomic level and overt anxiety as occurring at a conscious, cognitive, overt one. Various authors (e.g. Greer, 1999:237) have indicated an interplay between physiological predisposition, cognitive interpretation of a situation, and resulting autonomic response. Therefore, anxiety can be considered to have overt as well as covert forms of manifestation that interact with environmental cues, and these were the two variables measured.

A discussion regarding quantitative findings for covert and overt anxiety variables will follow, after which qualitative information will be discussed. Table 1 provides group designations that will facilitate understanding of results presented below.

Table 1: Group designations for pre- and postdiagnosis groups

\begin{tabular}{|l|l|l|l|l|}
\hline Group & Expl/Control & Pre-test & Intervention & Post-test \\
\hline Group 1 & E1 & Pre O1 & X & Post O2 \\
\hline Group 2 & C1 & Pre O3 & - & Post O4 \\
\hline Group 3 & E2 & - & X & Post O5 \\
\hline Group 4 & C2 & - & - & Post O6 \\
\hline \hline Group 5 & E3 & Pre 07 & X & Post 08 \\
\hline Group 6 & C3 & Pre O9 & - & Post 010 \\
\hline
\end{tabular}

Groups 1 to 4: pre-diagnosis, mammogram ( $N=18$ for each group)

Groups 5 and 6: post-diagnosis, radiation therapy ( $\mathrm{N}=8$ for each group)

\section{Covert anxiety}

There were significant differences between several of the pre- and post-diagnosis groups for this variable.

For the pre-diagnosis group there were significant differences between pre- and post-test mean scores within both Group 1 (O1 versus O2) and Group 2 (O3 versus O4). Differences within Group 1 indicate that the intervention had a mediating effect on the covert anxiety of patients waiting for mammogram results and possible diagnosis of cancer. However, as there were also significant differences for Group 2 it appears that there may have been a pre-test effect independent of the intervention. This group did not receive an intervention and there should thus have been no significant change. There were no statistically significant differences between pre-test scores (O1 versus $\mathrm{O} 3$ ) for Groups 1 and 2, therefore it can be assumed that the groups were matched and that this factor cannot account for findings. Further, both of these groups had lower anxiety scores at post-test than at pre-test, which confirms that they were matched.

Further comparisons attempted to shed light on the relative effects of the intervention versus pre-test. A comparison between post-tests of Groups 2 and 3 (O4 versus 05 ) confirmed the effect of the intervention, though also that there was a modifying effect from the pre-test. Further comparisons ( $\mathrm{O} 3$ versus $\mathrm{O} 5$; $\mathrm{O} 1$ versus 06) confirmed that both the intervention and pretests modified anxiety, whether patients were exposed to the pre-test alone (O3 versus $\mathrm{O} 4$ ) or intervention alone (O3 versus $\mathrm{O5}$ ), or a combination of pre-test and intervention (O1 versus $\mathrm{O} 2$; $\mathrm{O} 2$ versus $\mathrm{O} 5$ ). It would therefore appear that components in both the intervention and pre-test procedures had the action of reducing anxiety in pre-diagnosis patients, though exact mechanisms remain unknown.

In the delayed interview the role of personal contact was explored, and there does appear to be a trend toward the presence of empathic helpers having a modifying effect on anxiety while waiting for diagnosis or the first radiation treatment. This will be elaborated on in the following section on qualitative findings.

In the post-diagnosis group there were significant differences in pre- versus post-test scores for Group 5 (07 versus 08) but not Group 6 (O9 versus 010), which confirm that the intervention modified covert anxiety. Pre-test groups were also found to be matched (O7 versus O9). As the sample was small and a pretest - post-test design was used rather than a Solomon four group design, it cannot be conclusively stated that the intervention alone modified Covert anxiety. Factors such as pre-test sensitisation and even relief after the radiation procedure was over could have influenced post-test scores.

In conclusion, the differences observed between the 
experimental and control groups regarding pre- and post-diagnosis therefore appear to indicate that covert anxiety was reduced by the intervention and possibly the pre-tests, but not at which of these levels the change occurred.

\section{Overt anxiety}

As for the covert anxiety variable, as discussed above, significant changes in the overt anxiety variable were indicated in both pre- and post-diagnosis groups.

Regarding the pre-diagnosis group, differences in overt anxiety were exactly the same as those of covert anxiety, with the exception of the comparison between pretest scores of Group 2 (O3) and post-test scores of Group 3 (O5). This comparison was done to verify the effect of the intervention, versus a pre-test effect. Regarding the overt anxiety variable, there were no differences between these scores, therefore the effect of the intervention is confirmed and a pre-test effect is not apparent. A difference in scores was found for the covert anxiety variable, therefore confirming a pre-test effect for that variable.

For the post-diagnosis group, results were exactly the same for overt anxiety as for covert anxiety, as discussed previously. The effect of the intervention was confirmed.

\section{Qualitative findings}

Delayed interviews were done approximately one-year post-intervention, in order to obtain qualitative information. A randomly chosen member of each experimental group, which received a pre-test and intervention (Group 1, mammogram and Group 5, radiation) as well as the group which received only an intervention (Group 3, mammogram), was interviewed according to a structured list of questions.

Qualitative information from these interviews confirms that there was a subjective reduction in anxiety on exposure to the pre-test as well as intervention, though there were individual effects. Some subjects became aware of their tension levels due to how relaxed they felt after the intervention, while others were made aware by the items on the questionnaires. In all cases the awareness had a positive effect and motivated them to modify their anxiety levels. In some cases the subjects were extremely emotional and there was limited receptive ability for learning new information. In such cases the value of the intervention lay in the actual experiencing of it via the tester talking about it, rather than learning it and using it independently. Further, the presence of empathic people such as the tester, as well as nurses during the procedure of the mammogram or radiation, appeared to make a difference for all three of the subjects interviewed. On elaboration of how this effect was perceived to be useful, responses to interview questions were studied. Some of the responses to interview questions appear to indicate that the subjects felt less isolated due to the tester's presence, while others felt that the questionnaires and the 'technique' (intervention) were a welcome distraction from the adverse situation, and all commented on the positive effect of the emotional support they received from the tester.

The emphasis of the study was on anxiety at the preand post-diagnosis of breast cancer, as this is where the literature indicated that study is required. To this end, quantitative measures of anxiety were performed at these stages, and results indicated the effect of the cognitive-relaxation-visualisation intervention in reducing anxiety, as well as a pre-test effect with the prediagnosis group. The purpose of the delayed interviews was to assist in providing delayed qualitative information about the intervention, which could help in refining the intervention to make it more useful to women pre- and post-diagnosis of breast cancer. As a pre-test effect was not anticipated, investigating possible reasons for this was not a priority at a delayed interview stage but attempts were made to use qualitative information gleaned from these interviews, in order to explain the effects observed. Conclusions about qualitative as well as previously discussed quantitative findings will now be evaluated, in the context of limitations usually found in stress-illness research.

\section{DISCUSSION}

The present study was subject to the difficulties of all stress-illness research. However, for both groups studied here, attempts were made to control for extraneous factors. Samples were matched in terms of age, gender, marital and socio-economic status. Factors such as clinical depression as well as concurrent medi 
cal conditions such as diabetes were considered exclusion criteria. Further, subjects for the pre-diagnosis group were drawn from two clinics that were located in the same geographic area and where the same procedures were used to administer mammograms as well as to notify patients of results. All of the radiation therapy patients were from the same oncology centre. Experimental and control groups were therefore as homogenous as possible. The same individual performed the psychometric testing as well as the intervention to promote consistency. Qualitative information was also obtained approximately a year after the intervention in order to shed further light on quantitative findings. Finally, as large a sample as possible was obtained in each case.

On analysis of quantitative and qualitative findings which have previously been detailed, within the context of the limitations discussed above, it would seem that this study was subject to the same limitations experienced by other stress-illness researchers. The postdiagnosis group had a small sample size, which means that findings cannot be generalised. The experimental groups were also undergoing different stressors that are associated with differing anxiety levels. Clearly these differences must be taken into account when assessing relative effects of the intervention and/or pre-test on modifying anxiety.

For the pre-diagnosis group a larger sample was obtained in an attempt to improve validity and generalisability. Randomisation in terms of allocation to Experimental or Control groups was again practised. There were no statistically significant differences among pre-tests of the mammogram Control as well as Experimental groups, therefore the samples can be assumed to be matched.

A possible pre-test phenomenon occurred in the prediagnosis groups. This has been found by other researchers and does not invalidate a study. Rather, it limits generalisability of findings, as well as not being able to distinguish between whether the intervention and/or the intervention resulted in change. Qualitative information has shed some light as to why these effects happened and will assist in designing future studies to clarify these issues.

It would appear that the pre-test sensitised the patients to the intervention, and perhaps acted as an intervention itself. Kazdin (1980:45) as well as Mungas and Walters (1979:217) have both described pre-test sensitisation in stress-health research, and that this phenomenon does not threaten internal validity but results can later only be generalised to the pre-test Experimental/Control groups.

The same tester and procedure were used throughout, to improve reliability and validity. The IPAT questionnaire was used as it is standardised for use in South Africa and has good reliability (Owen \& Taljaard, 1989:3) as well as validity (Cattell, 1963:2).

In the study by Mineka and Kelly (1989:264) a cognitive-behavioural intervention was found to reduce anxiety in breast cancer patients undergoing the first two weeks of radiation therapy. In the case of this study the cognitive component may have partly been the pretest questionnaires which several respondents reported as making them think about their circumstances and thought processes, and often realising that they were "not as anxious as they could have been", or as anxious as others, if they had answered affirmatively to more questions on the first section of the IPAT measure. (This section measures overt thoughts and symptoms of state anxiety). The instruction for, and use of the relaxation technique, which involved diaphragmatic breathing and visualisation, as used successfully by Simonton (Kidman, 1983:34), also entails a cognitivebehavioural component. Again, it is difficult to identify exactly which part of the intervention process was responsible for reduced overt anxiety. It may have been the presence of an empathic tester before treatment, the Hawthorne effect where subjects want to 'please' or impress the tester such as by appearing less overtly anxious, the cognitive component of the intervention, the relaxation part of the intervention, the effect on perception and cognition of filling out several questionnaires, or a combination of any of these variables which resulted in the shifts.

It would appear that the presence of an empathic tester had anxiolytic effects, irrespective of the actual content of the interaction between patient and tester. This remains to be further investigated, though the personcentred approach of psychotherapy advocated by Carl Rogers (Maddi, 1989:154) and which incorporates components such as 'unconditional positive regard' of 
the client as well as 'accurate empathy' in one's manner, has proven to have positive effects on a client's well-being.

\section{CONCLUSION}

The present study was the first of it's kind in South Africa, also the first to assess the effect of a psychological intervention at pre-diagnosis level as opposed to post-diagnosis. This study also assessed an intervention where components such as relaxation, visualisation and cognitive modification of a sense of control were combined into a single intervention rather than assessed individually, as other studies have done. Further, delayed qualitative information regarding the intervention was also obtained.

While all of these factors were relevant, there were limitations to this study that in all likelihood influenced the findings. It was indicated that the intervention had an effect on anxiety, but there were also pre-test effects. In order to counter these difficulties, and facilitate obtaining of more conclusive results, a number of recommendations are made for future studies.

Firstly, it is recommended that additional measures of the anxiety variables be utilised. This will assist in separating pre-test effects from those of the intervention, also in identifying the components of anxiety that were modified. Secondly, additional variables such as mood (depression) and temperament (hardiness) could be measured, and provide a clearer impression of the individuals being assessed. Assessment of temperament, particularly, should also indicate which individuals are more likely to be stress-resistant and therefore less likely to experience high anxiety levels during illness. Further study of the coping mechanisms used by such individuals may also assist researchers in developing interventions for those who are not constitutionally stress-resistant. Another issue to be borne in mind is that of third factors, such as the effect of social support or work problems, on the emotional state of the patient. These factors can never be entirely controlled for, though additional questionnaires could provide information on such factors, which would aid in interpretation on results. There is the complication, however, that individuals already stressed by medical procedures, are generally unwilling to complete large volumes of questionnaires.
A further suggestion is that samples be modified according to age, to investigate whether younger women experience the possibility of a cancer diagnosis as more stressful, for example. Different cultures may also experience medical procedures in unique ways, and future studies should address this.

In addition, though sample size is a common difficulty in stress-illness research, it is suggested that larger samples be obtained where possible.

No immune measures were planned, as there are many studies where accuracy of immune measures is questioned due to factors such as difficulty separating whether the events of days before as opposed to the present situation could be responsible for immune changes observed (Levy, 1991:213). Immunologists are also not certain exactly what to measure to accurately reflect immune defences regarding stress and health (Rice, 1998:169). However, should accurate measures of immune function become available, these could be used concurrently with psychometric evaluation in order to facilitate triangulation of findings. In addition, the use of measures such as biofeedback or blood pressure measurement may assist in monitoring relaxation or tension levels, though the suitability of these as reliable instruments for these purposes will have to be assessed via a literature study.

Finally, this study was the first of it's kind and was aimed at contributing to the cancer intervention literature, as well as initiating further study into combined interventions at pre- and post-diagnosis levels. While there is inconclusive proof of the efficacy of the combined intervention, there is indication that the presence of an empathic tester at a time of stressful medical procedure is anxiolytic in nature. It is known that anxiety interferes with cognitive processing (Singh, 1999:61) and this may be the reason for the subjects not absorbing the full effect of the intervention. Ongoing teaching of the intervention via group and individual contact may therefore be more useful during treatment, and training medical staff to be empathic and explain procedures, as well as in the instruction of simple relaxation techniques such as deep diaphragmatic breathing, will also prove useful in reducing patient distress.

While some studies (Carey \& Burish, 1987:733) indi- 
cate that patients prefer interventions conducted by trained professionals, these studies also indicate a preference for individual contact with an empathic individual. Other studies (Hyodo et al. 1999:397; Samarel, Fawcett, Davis \& Ryan, 1998:1370) confirm the importance of empathy when providing counselling preand post-surgery, or on admission to hospital.

In conclusion, while the cognitive-relaxation-visualisation intervention designed for this study may not have proven as successful in reducing anxiety as had been envisaged, it did have a degree of effect and the use of a combined intervention, also at a pre-diagnosis level, was unique. Further, the unexpected sensitising effect of the pre-test, which is hypothesised as being mainly due to accurate empathy from the tester, has major implications for those in the 'helping professions.' From the results of this study it is strongly recommended that medical personnel be trained in empathy and explanation skills, and then possibly train others in a 'train the trainer' approach which has been proven workable in stress-inoculation training (Meichenbaum \& Turk, 1982:56). In a country such as South Africa, with a large rural population and limited professional resources, such an application of the results of this study could prove invaluable in ameliorating the distress associated with breast cancer - the second most common cancer in South Africa.

\section{REFERENCES}

AMBLER, N; RUMSEY, N; HARCOURT, D; KHAN, F; CAWTHORN, S \& BARKER, J 1999: Specialist nurse counsellors interventions at the time of diagnosis of breast cancer: comparing 'advocacy' with a conventional approach. Journal of Advanced Nursing, 29(2):445-453.

BRYANT, RA; SACKVILLE, T; DANG, ST; MOULDS, M \& GUTHRIE, R 1999: Treating acute stress disorder: an evaluation of cognitive behaviour therapy and supportive counselling techniques. American Journal of Psychiatry, 156(11):1780-6.

CANSA 2002: Cansa research: Breast Cancer. Retrieved from World Wide Web on 27 March 2002: http://www.cansa.co.za/registry-breast.asp.

CAREY, MP \& BURISH, TG 1987: Providing relaxation training to cancer chemotherapy patients: A comparison of three delivery techniques. Journal of Consulting and Clinical Psychology, 55(5):732-737.

CATTELL, RB 1963: Personality, role, mood and situational per- ception: A unifying theory of modulators. Psychological Review, 70:1-18.

CIMPRICH, B 1999: Pretreatment symptom distress in women newly diagnosed with breast cancer. Cancer Nursing, 22(3):185-194. CONSTANTINI, M; MUSSO, M; VITERBORI, P; BONCI, F; DEL MASTRO, L; GARRONE, O; VENTURINI, M \& MORASSO, G 1999: Detecting psychological distress in cancer patients: validity of the Italian version of the Hospital Anxiety and Depression Scale. Support Care Cancer, 7(3):121-7.

EDELMAN, S; LEMON, J; BELL, DR \& KIDMAN, AD 1999: Effects of group CBT on the survival time of patients with metastatic breast cancer. Psychooncology, 8(6):474-481.

EVERLY GS \& ROSENFELD, R 1981: The nature and treatment of the stress response. New York: Plenum Press.

FARRAGHER, B 1998: Psychiatric morbidity following the diagnosis and treatment of early breast cancer. Ir Journal of Medical Science, 167(93):166-9.

FRIED, R 1993: The psychology and physiology of breathing: In behavioural medicine, clinical psychology and psychiatry. New York: Plenum Press.

GREER, S 1999: Mind-body research in psychooncology. Advanced Mind Body Medicine, 15(4):236-244.

HELLBOM, M; BRANDBERG, Y; GLIMELIUS, B \& SJODEN, PO 1998: Individual psychological support for cancer patients: utilisation and patient satisfaction. Patient Education Counselling, 34(3):247-256.

HYODO, I; EGUCHI, K; TAKIGAWA, N; SEGAWA, Y; HOSOKAWA, Y; KAMEJIMA, K \& INOUE, R 1999: Psychological impact of informed consent in hospitalised cancer patients. A sequential study of anxiety and depression using the hospital anxiety and depression scale. Support Care Cancer, 7(6):396-9.

KAZDIN, AE 1980: Research Design in Clinical Psychology. New York: Harper \& Row.

KIDMAN, B 1983: A gentle way with cancer. London: Century Publishing.

LEVY, S 1991: Behavioural and immunological host factors in cancer risk. (In: PM McCabe; N Schneiderman; TM Field \& JS Skyler eds 1991: Stress, coping and disease. New Jersey: Erlbaum). MADDI, SR 1989: Personality Theories: A comparative analysis. Illinois: Dorsey Press.

MCQUELLON, RP; WELLS, M; HOFFMAN, S; CRAVEN, B; RUSSELL, G; CRUZ, J; HURT, G; DECHATELET, P; ANDRYKOWSKI, MA \& SAVAGE, P 1998: Reducing distress in cancer patients with an orientation programme. Psychooncology, 7(3):207-217.

MEICHENBAUM, D \& TURK, S 1982: Stress inoculation training. USA: Pergamon Press.

MINEKA, S \& KELLY, KA 1989: The relationship between anxiety, 
lack of control and loss of control. (In: A Steptoe \& A Appels eds 1989: Stress, Personal control and Health. New York: Wiley \& Sons). MOSE, S; RAHN, AN; BUDISCHEWSKI, KM; ZANDER HEINZ, AC; ADAMIETZ, IA; BORMETH, S; THILMANN, C \& BOTTCHER, HD 1999: The effect of adjuvant radiotherapy on the mental health of female patients with a breast-conserving operated breast carcinoma. Strahlenther Onkologie, 175(3):112-8.

MUNGAS, DM \& WALTERS, HA 1979: Pretesting effects in the evaluation of social skills training. Journal of Consulting and Clinical Psychology, 47:216-218.

OKTAY, JS 1998: Psychosocial aspects of breast cancer. Lippincotts Primary Care Practice, 2(2):149-159.

OWEN, K \& TALJAARD, JJ 1989: Handbook for the use of Psychological and Scholastic tests of the IPER and the NIPR. Pretoria: Gutenberg.

RICE, PL 1998: Health Psychology. New York: Brooks/Cole.

RUSTEN, T; WIKLUND, I; HANESTAD, BR \& MOUM, T 1998: Nursing intervention to increase hope and quality of life in newly diagnosed cancer patients. Cancer Nursing, 221(4):235-245.

SAMAREL, N; FAWCETT, J; DAVIS, MM \& RYAN, FM 1998: Effects of dialogue and therapeutic touch on preoperative experiences of breast cancer surgery: an exploratory study. Oncology Nurses Forum, 25(8):1369-1376.

SCHLEBUSCH, L \& VAN OERS, M 1999: Psychological stress, adjustment and cross-cultural considerations in breast cancer patients. SA Journal of Psychology, 29(1):30-35.

SINGH, R 1999: The relationship between stressful life events, locus of control and the onset of breast cancer. Rand Afrikaans University: Johannesburg. (Unpublished Masters Dissertation).

SPIEGEL, D; MORROW, GR; CLASSEN, C; RAUBERTAS, R; STOTT, PB; MUDALIER, N; PIERCE, HI; FLYNN, PJ; HEARD, L \& RIGGS, G 1999: Group psychotherapy for recently diagnosed breast cancer patients: a multicenter feasibility study. Psychooncology, 8(6):482-293.

SPSS 1999: SPSS Base 10.0 Applications Guide. USA: SPSS Inc. SULS, J; DAVID, JP \& HARVEY, JH 1996: Personality and Coping: Three generations of research. Journal of Personality, 64(4):712727.

ZUCKERMAN, M; KNEE, CR; KIEFFER, SC; RAWSTHORNE, L \& BRUCE, LM 1996: Beliefs in realistic and unrealistic control: Assessment and implications. Journal of Personality, 64(4):435464. 